\title{
Improving urban flood estimation and flood risk assessment using landscape metrics
}

\author{
James Miller ${ }^{1 a}$, Gianni Vesuviano ${ }^{1}$ and Elizabeth Stewart ${ }^{1}$ \\ ${ }^{1}$ UK Centre for Ecology \& Hydrology, Crowmarsh Gifford, Oxfordshire, OX10 8BB, United Kingdom.
}

\begin{abstract}
Urbanization creates impervious coverage and increases peak flows during storm events. Flood estimation methods in the United Kingdom characterize these impacts using a weighted measure of catchment urban land cover, but research suggests that consideration of spatial effects could improve lumped catchment modelling of storm runoff. This paper employs spatially explicit landscape metrics alongside lumped catchment descriptors to assess the potential for improving flood estimates in urbanised catchments over existing methods used to assess flood risk. Such metrics are found to provide a useful means of improving flood estimates and flood risk evaluation in ungauged urban catchments, particularly smaller urban catchments. Results have pointed to the potential value in refining catchment datasets to exclude less-suitable data in order to reduce associated uncertainty in flood estimates. They further demonstrate the value of considering spatial arrangements of urban land cover. We conclude that it is not always beneficial to have more data, but to have the most suitable data for the application, and that this could be dependent on the scale or level of urbanization. The study of landscape metrics is an emerging area of research for bridging the gap between lumped and distributed hydrological modelling, and improving urban flood risk estimates.
\end{abstract}

\section{Introduction}

The process of urbanization reduces areas of natural surfaces and increases the coverage of impervious surfaces within a catchment, thereby reducing infiltration of rainfall to subsurface soils and affecting soil flow pathways (Roy and Shuster, 2009). Additionally, through urban drainage, the resulting increases in runoff are conveyed more efficiently through the catchment (Boyd et al., 1994). This has a number of effects on the resulting runoff in storm events, the increase in peak flows being the primary concern for urban planners (Miller et al., 2014). Planning for urban infrastructure to convey storm flows and protect existing developments requires quantitative assessment of how 'natural' or 'rural' flows under storm conditions are likely to change under variably urbanized conditions.

A number of countries undertake flood estimation methods that are able to provide peak flow estimates for ungauged catchments, accounting for urbanization effects. Flood estimates for ungauged catchments are routinely based on derived relationships between peak flows and various catchment descriptors in both the UK (Environment Agency, 2017a) and internationally (Feaster et al., 2014). These approaches, such as the UK Flood Estimation Handbook (IH, 1999), generally apply a lumped catchment approach to assessing urban effects, given that most catchment descriptors do not contain spatially explicit information, and assume a fixed relationship between extent of urbanization and increase in peak flow. The extent of urbanization is quantified as a lumped measure of how widespread impervious surfaces have become across the catchment (Redfern et al., 2016). Such lumped measures do not consider the spatial arrangement of urbanized surfaces, which is shown in many modelling studies to impact upon the timing and magnitude of peak flows (Mejía and Moglen, 2009). Empirical research by Miller \& Hess (2017) has shown that a non-distributed urban land cover descriptor does not mirror the variation in peak flows potentially driven by differences in spatial layout between urban catchments.

Spatially explicit metrics of catchment land cover have been highlighted as suitable for representing the hydrological impacts of urbanization (Ogden et al., 2011) but uptake of such spatial metrics outside of landscape ecology has been limited. Landscape metrics were developed in ecology to characterize the composition and spatial configuration of patches of land cover classes in order to link ecological processes and patterns of species movement and distribution (Turner et al., 2001). As such, they offer potential improvements over lumped catchment descriptors that are unable to account for spatial factors of land cover distribution or layout within a catchment. Recent research by Oudin et al. (2018) for example has shown that such metrics can help with understanding the

${ }^{\mathrm{a}}$ Corresponding author: $\underline{\text { millj@,ceh.ac.uk }}$

DOI 10.3311/FLOODRisk2020.5.1 
variability of urbanization impacts and how spatial configuration could be effective for mitigating the impacts of urbanization.

The reliance of UK flood estimation methods on lumped catchment approaches and spatially generalized catchment data has led to concerns that this limits the performance of methods, particularly in small urban catchments (Faulkner et al., 2012; Miller \& Hess, 2017; Vesuviano \& Miller, 2019). These methods use the index of urban exent - URBEXT - as a means for estimating impervious surfaces effects within the catchment (Bayliss, 1999). Miller \& Brewer (2018) highlighted the potential for applying landscape metrics to improve flood estimates but results were limited to an exploratory analysis with limited data. In order to better understand the potential for spatially explicit landscape metrics in flood estimation they recommended wider testing across a wider range of catchment scales and a wider geographical scope.

The aim of this paper is to undertake a national assessment of the potential for the use of landscape metrics in quantifying the impacts of urbanization and improving estimates of the median annual flood in urbanized catchments. To achieve this aim three objectives are set: i) quantify landscape metrics across suitable UK urbanized catchments, ii) recalibrate urban adjustment methods and assess performance of $Q M E D$ estimates, and iii) assess potential impacts on design flood estimates and flood risk.

\section{UK flood estimation methods}

In the UK, the Flood Estimation Handbook (Institute of Hydrology, 1999) describes a statistical flood estimation method and a lumped rainfall-runoff flood estimation method. Both can be used to estimate floodfrequency relationships at sites with or without the additional use of gauged river flow data. The FEH statistical method, significantly revised by Kjeldsen et al. (2008), is an index-flood method in which the site-specific scaling factor is the median annual flood, $Q M E D$. If sufficient, high-quality gauged data are available, $Q M E D$ is estimated as the median of the annual maximum peak flow (AMAX) series, using an October-September water year. If not, $Q M E D$ is estimated from an equation based on digital catchment descriptors (Bayliss, 1999, which are mapped for the UK at 50-metre resolution):

$$
\begin{gathered}
\text { QMED }= \\
8.3062 A R E A^{0.8510} 0.1536^{\frac{1000}{S A A R}} F^{2} A R L^{3.4451} 0.0460^{\text {BFIHOST }^{2}}(1)
\end{gathered}
$$

where $A R E A$ is the upstream catchment area in $\mathrm{km}^{2}$, $S A A R$ is the 1961-1990 catchment mean annual rainfall in $\mathrm{mm}, F A R L$ is a dimensionless index of flood attenuation from reservoirs and lakes and BFIHOST is an estimate of the proportion of baseflow to total flow, based on soil type. The factorial standard error of the FEH $Q M E D$ equation is 1.431, meaning that about 1-in-20 QMED estimates made by this equation are more than double or less than half of the true value.

Model errors in the FEH $Q M E D$ equation are spatially correlated. Hence, a $Q M E D$ estimate made using the equation must be adjusted via the "donor transfer" procedure. In this, the model error (i.e. ratio of gauged to estimated $Q M E D$ ) is calculated at several nearby gauged sites (usually six), a weighted average of model errors is taken to estimate the model error at the site of interest, and the $Q M E D$ estimate at the site of interest is revised accordingly. The procedure is described in detail by Kjeldsen et al. (2014).

The FEH $Q M E D$ equation assumes that the catchment is rural. An urban adjustment factor $(U A F)$ for $Q M E D$ was implemented in the original FEH methods (IH, 1999), updated by Kjeldsen (2010) and recently recalibrated by Wallingford HydroSolutions (2016) - herein termed the 'current' method as its used operationally by hydrological engineers. The urban adjustment factor is calibrated to the ratio between QMED as estimated from gauged data $\left(Q M E D_{O B S}\right)$ and as-rural QMED estimated using equation 1 above $\left(Q M E D_{R U R A L}\right)$ - this ratio is herein termed the urban growth factor (UGF) and detailed in Table 1. This is presented here in its "default" form, in which variables (except catchment descriptors) are set at their default values and urban area is estimated from the catchment descriptor URBEXT 2000 (Bayliss et al., 2006):

$$
\begin{gathered}
\text { UAF }=\left(1+0.4701 \text { URBEXT }_{2000}\right)^{1.25}(P R U A F)^{1.33} \\
0.4701 \text { URBEXT }_{2000}\left(\frac{P R U A F=1+}{69.366-65.686 \text { BFIHOST }}-1\right)
\end{gathered}
$$

BFIHOST, measuring soil permeability, is included in this adjustment as sealing a more-permeable soil reduces infiltration by more than sealing a less-permeable soil.

Once $Q M E D$ is estimated, rarer floods are estimated as multiples of $Q M E D$, according to general index-flood methodology:

$$
x_{T}=Q M E D z_{T}
$$

where $x_{T}$ is the magnitude of the $T$-year flood peak and $z_{T}$ is the growth factor of the $T$-year flood peak i.e. how many times larger than $Q M E D$ it is.

\section{Method}

\subsection{Study area - urban catchments}

Suitable catchments with associated hydrometric data were selected from the National River Flow Archive (NRFA) Peak Flow dataset, version 7, according to a range of criteria. The NRFA Peak Flow dataset stores annual maximum peak flows, peaks-over-threshold, catchment descriptors and catchment boundaries for approximately 1000 catchments $(n=957)$ in the UK. The information used and the criteria applied to refine the dataset are detailed in Table 1.

Criteria were selected to refine the overall list of 957 stations to yield data suitable for calibration of an urban adjustment factor. The primary criterion was that a catchment was considered as urbanized. For this, we used a threshold of $3 \%$ outlined by the value of $U R B E X T$ for the year 2000 (URBEXT2000) - this value was also used by Kjeldsen et al. (2008). A base flow index (BFIHOST) of less than 0.65 was selected to remove those catchments 
that had a groundwater dominated flow regime, as flow peaks in such catchments are primarily driven by baseflow (Faulkner et al., 2012). Only catchments with 10 or more years of AMAX data and with data to at least 2015 were selected, to ensure that flows were contemporary and of sufficient length to make good estimates of current observed $Q M E D$. These criteria refined the initial list to 141 catchments.

\begin{tabular}{|c|c|}
\hline $\begin{array}{l}\text { Variable and } \\
\text { description }\end{array}$ & Criteria \\
\hline $\begin{array}{l}\text { URBEXT } \\
\text { Extent of urban and } \\
\text { suburban cover }\end{array}$ & $U R B E X T_{2000} \geq 0.03$ \\
\hline $\begin{array}{c}\text { BFIHOST } \\
\text { Baseflow index derived } \\
\text { from HOST soils data }\end{array}$ & BFIHOST $<0.65$ \\
\hline Record length & Length $>10$ years \\
\hline Record end & $\begin{array}{l}\text { Available to at least } \\
2015\end{array}$ \\
\hline $\begin{array}{c}\text { FEH indicative suitability } \\
\text { Quality of flow data }\end{array}$ & $\begin{array}{l}\text { Suitable for QMED } \\
\text { or Pooling }\end{array}$ \\
\hline $\begin{array}{l}\text { Urban Growth Factor } \\
(U G F) \\
\text { Difference between } \\
\text { observed } Q M E D \text { and the as- } \\
\text { rural estimate }\end{array}$ & $\begin{array}{c}\left(Q M E D_{O B S} /\right. \\
\left.Q M E D_{R U R A L}\right)>0.90^{*}\end{array}$ \\
\hline
\end{tabular}

Table 1. Variables used to refine NRFA Peak Flow dataset and criteria applied. (* where $Q M E D_{O B S}$ are deemed to be accurate).

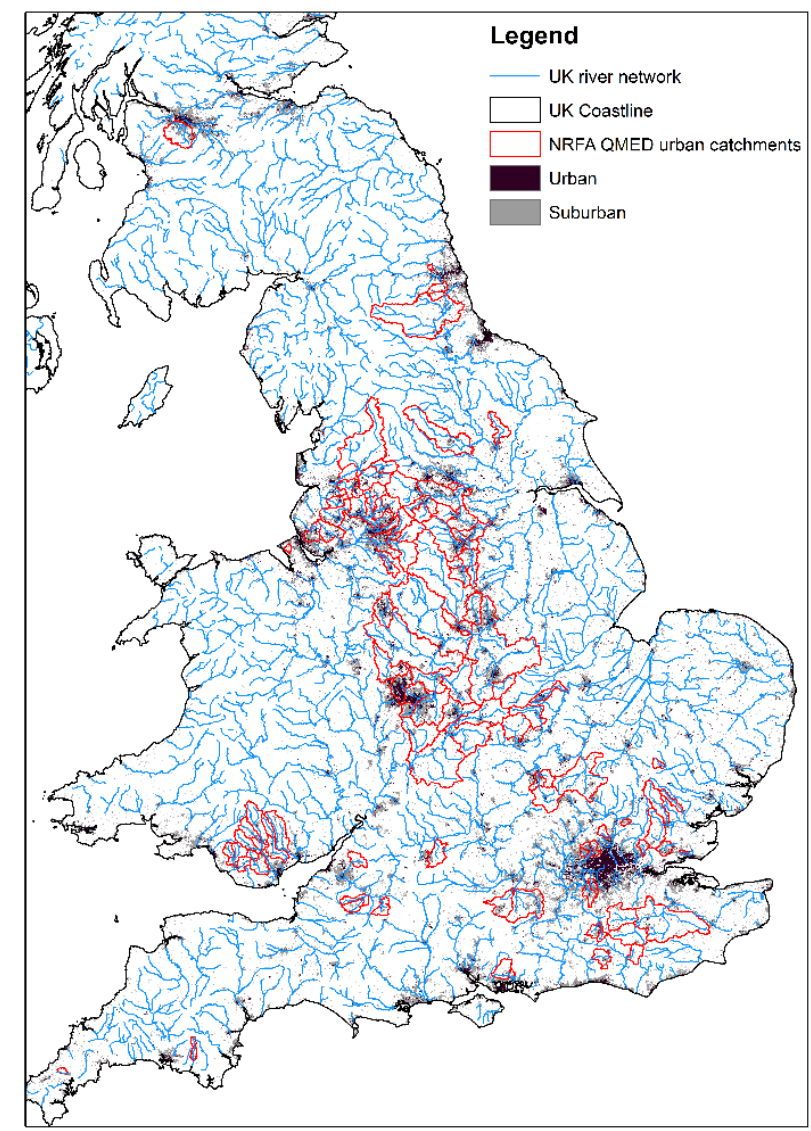

Figure 1. Selected NRFA catchments (116) that met the study criteria. Urban and Suburban land cover is derived from UK LCM2015 (Rowland et al. 2017).
For an additional check to improve model suitability, we removed all catchments where the FEH statistical estimate for as-rural $Q M E D$ was more than $10 \%$ higher than the observed $Q M E D$ derived from AMAX data, if there was good evidence of accurate gauging of high flows above $Q M E D$. This additional criterion was applied due to concern over the effect of calibrating the urban adjustment factor to catchments where the as-rural estimate was significantly higher than the observed $Q M E D$, hence where the urban adjustment factor was significantly less than 1. Urbanization should be expected to increase $Q M E D$, but the presence of $U G F$ s below 1 was noted in the Flood Estimation Handbook during the original calibration of $U A F(\mathrm{IH}, 1999)$ for some $42 \%$ of the 123 urban sites used in its calibration. This may be due in part to uncertainty in the as-rural estimate for $Q M E D$ - the factorial standard error of the $Q M E D$ equation published in the FEH was 1.549, meaning that just over 1-in-6 estimates were more than $50 \%$ above the true value. A rational approach to rectify this issue in this study was to remove catchments where the estimated $U G F$ (Table1) was less than 0.9. This had the effect of removing a further 25 catchments.

The final result of applying all criteria was a subset of 116 catchments across Great Britain (Figure 1). It is clear from the distribution of the selected 116 catchments that key areas such as southwest England, East Anglia, central and north Wales, and Scotland do not contribute much data. This is due to a combination of all of the criteria applied, but primarily the URBEXT and BFIHOST criteria. Further, it is clear that there is a wide degree of variability in urbanization levels across the 116 catchments; the majority of highly urbanized catchments are located in the Midlands or northwest England.

\subsection{Landscape metrics}

Mapping of landscape metrics for the selected catchments used the UK Land Cover Map product for 2015 (LCM2015), developed by the UK Centre for Ecology \& Hydrology (Rowland et al. 2017). The product is based on the mapping classes defined in the 2007 report (Morton et al., 2007) and for the purposes of this study we employ the Urban and Suburban classes: Suburban areas have a mix of housing and greenspace, while Urban areas are dominated by continuous development and minor greenspace. UK mapping of these classes, at a 50-metre gridded resolution, was clipped using the NRFA catchment boundaries for the 116 selected catchments.

Landscape metrics were calculated for the selected catchments using the freely available Fragstats software package (McGarigal and Marks, 1994), which is a tool for quantifying landscape structure through geo-spatial analysis of land cover (Frazier \& Kedron, 2017). Fragstats was selected because it is a relatively accessible tool that works with raster data, calculates all required metrics (McGarigal et al., 2009) and has demonstrated its performance in urban areas (Grafius et al., 2018). The range of landscape metrics and catchment descriptors selected is detailed in Table 2 . 
For each landscape metric, values were calculated considering only suburban patches (denoted by a subscript $\mathrm{Sub}$ after the landscape metric), only urban patches (subscript $U r b$ ) and both (subscript $U r b S u b$ ).

A number of related landscape metrics based on the proximity index ( $P X$ : Eq. 5) were also used. $P X$ indexes the hydrological distance from all Urban and Suburban patches to the outlet. This was calculated in ArcGIS using methods outlined by Miller \& Brewer (2018)

$$
P X=\sum{\frac{A_{k}}{m d o_{k}}}
$$

Where $A_{k}$ is the area of patch $k$ and $m d o_{k}$ is the mean distance to outlet of patch $k$.

\begin{tabular}{|c|c|}
\hline $\begin{array}{l}\text { Landscape metric } \\
\text { (Fragstats) }\end{array}$ & Description \\
\hline CONTIG* & $\begin{array}{l}\text { Spatial connectedness, or contiguity, of } \\
\text { cells within a grid-cell patch }\end{array}$ \\
\hline CLUMPY & $\begin{array}{l}\text { Deviation of the proportion of like } \\
\text { adjacencies involving the } \\
\text { corresponding class from that expected } \\
\text { under a spatially random distribution }\end{array}$ \\
\hline COHESION* & $\begin{array}{l}\text { Physical connectedness of the } \\
\text { corresponding patch type }\end{array}$ \\
\hline PLAND* & $\begin{array}{l}\text { Percentage of the landscape comprised } \\
\text { of the corresponding patch type }\end{array}$ \\
\hline CONTAG & $\begin{array}{l}\text { Extent to which patch types are } \\
\text { aggregated or clumped as a percentage } \\
\text { of the maximum possible }\end{array}$ \\
\hline$L S I$ & $\begin{array}{l}\text { Percentage of total landscape area } \\
\text { comprised by the largest patch }\end{array}$ \\
\hline COHESION & Physical connectedness of all classes \\
\hline $\begin{array}{l}\text { Catchment } \\
\text { descriptor (FEH) }\end{array}$ & \\
\hline AREA & Catchment drainage area $\left(\mathrm{km}^{2}\right)$ \\
\hline BFIHOST & Base Flow Index from HOST class \\
\hline FARL & Flood attenuation index of rivers/lakes \\
\hline FPEXT & Floodplain extent \\
\hline SAAR & 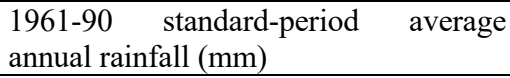 \\
\hline SPRHOST & $\begin{array}{l}\text { Standard percentage runoff from HOST } \\
\text { class }\end{array}$ \\
\hline$D P L B A R$ & Mean drainage path length \\
\hline DPSBAR & Index of catchment steepness \\
\hline PROPWET & Index of proportion of time soils are wet \\
\hline URBEXT $T_{1990}$ & $\begin{array}{l}\text { Index of fractional urban extent - year } \\
1990\end{array}$ \\
\hline$U_{U R B E X T_{2000}}$ & $\begin{array}{l}\text { Index of fractional urban extent }- \text { year } \\
2000\end{array}$ \\
\hline$U R B E X T_{2015}$ & $\begin{array}{l}\text { Index of fractional urban extent - year } \\
2015\end{array}$ \\
\hline$U R B C O N C_{2000}$ & $\begin{array}{l}\text { Index of concentration of urban and } \\
\text { suburban land cover - year } 2000\end{array}$ \\
\hline$U R B L O C_{2000}$ & $\begin{array}{l}\text { Index of location of urban and suburban } \\
\text { land cover - year } 2000\end{array}$ \\
\hline$U R B L O C_{2015}$ & $\begin{array}{l}\text { Index of location of urban and suburban } \\
\text { land cover - year } 2015\end{array}$ \\
\hline
\end{tabular}

Table 2. Standard landscape metrics and catchment descriptors used as possible variables in refining the urban adjustment factor equation.

In order to avoid very high values of $P X$ for patches located at or near the catchment outlet a minimum patch flow path length ( $m d o$ ) of $1 \mathrm{~km}$ was assigned. Without this, even modestly sized patches with an mdo under $1 \mathrm{~km}$ could have disproportionately high $P X$ values due to the scaling effect in the calculation. The $P X$ metric was also transformed to provide more spatial consistency between catchments. Normalizing patch area $A_{k}$ and patch flow path length $m d o k$ by FEH catchment descriptors for catchment area $(A R E A)$ and mean catchment drainage path length $(D P L B A R)$, respectively, provided a normalized, unit-less proximity index $P X_{N}$ :

$$
P X_{N}=\sum \frac{A_{k} / A R E A}{m d o_{k} / D P L B A R}
$$

Further normalization was also provided by standardizing the calculated $P X$ metric by either catchment length $(D P L B A R)($ Eq. 7$)$ or catchment area (AREA) (Eq. 8):

$$
\begin{gathered}
P X S L=\sum \frac{A_{k} / m d o_{k}}{D P L B A R} \\
P X S A=\frac{A_{k} / m d o_{k}}{A R E A}
\end{gathered}
$$

Lastly, the $P X$ metric was weighted to reflect the weighting of urbanized surfaces in the URBEXT equation:

$$
\text { PXURBEXT }=\sum \frac{A(\text { Urban })_{k}}{\text { mdo(Urban })_{k}}+0.5 \frac{A(\text { Suburban })_{k}}{\text { mdo(Suburban })_{k}}
$$

To complete the range of landscape metrics produced, and enable a full comparison with FEH catchment descriptors, the urban location index URBLOC (Table 2) was calculated for the selected catchments using land cover in 2015. URBLOC indexes the location of urban and suburban land cover and applies a similar weighting to URBEXT. The calculation follows that published by Bayliss (1999) in the FEH catchment descriptors volume of the FEH.

\subsection{QMED}

"Urban" $Q M E D$ was calculated for all catchments as the median of at-site AMAX data, while "as-rural" $Q M E D$ was estimated using the 'current' FEH QMED equation (Eq. 1) and donor transfer from the six nearest suitable rural $\left(U R B E X T_{2000}<0.03\right)$ donor catchments. The estimated urban growth factor (UGF) was calculated as the gauged urban estimate of $Q M E D$ divided by the ungauged "as-rural" $Q M E D$ estimate. Next, the correlation between the natural logarithm of estimated $U G F$, and each of the landscape metrics and catchment descriptors listed in Table 2, in a range of transformations (untransformed, inverse, logarithm, exponential, square and square-root) was found. Estimated $U G F$ was then fitted to combinations of landscape metrics and catchment descriptors with which it had high correlation, using ordinary least-squares, regression to produce models giving a predicted urban adjustment factor, $U A F$, that can be used to correct the as-rural QMED. 


\subsection{Model assessment}

Models were assessed through standard deviation of residuals, sum-of-squared errors, sum-of-absolute errors and range of residuals, in each case comparing gauged and modelled estimates of $\ln (Q M E D)$, the natural logarithm of $Q M E D$. New models are assessed against each other, as well as the urban adjustment procedure implemented in the current FEH statistical method and the baseline no adjustment or "as-rural" case. Throughout, the growth factor obtained by dividing the urban $Q M E D$ by rural $Q M E D$ is referred to as the Urban Growth Factor ( $U G F)$ and the model output is referred to as the Urban Adjustment Factor $(U A F)$.

\section{Results}

\subsection{Landscape metrics}

Landscape metrics were calculated for all selected catchments. Applying the minimum $1 \mathrm{~km}$ distance for flow path lengths was a successful way of limiting the influence of large contiguous patches located near to or bordering the catchment outlet location, stopping the severe increase in $P X$ value for catchments where the minimum flow path length was less than $1 \mathrm{~km}$, which would previously act to increase $P X$ disproportionately. Results showed, however, that $P X$ values can remain high for large and highly urban catchments, such as 28081, which encompasses much of Wolverhampton and Birmingham, (Table 3: 102.4); this is due to near continuous urban land cover that results in a large urban patch whose most downstream point is located at the catchment outlet (Figure 2).

\begin{tabular}{|c|c|c|c|c|}
\hline & 28080 & 28081 & 28039 & 69043 \\
\hline$A R E A$ & 795.1 & 175.0 & 73.7 & 72.3 \\
\hline$U R B E X T_{2015}$ & 0.40 & 0.66 & 0.46 & 0.42 \\
\hline$U R B L O C_{2015}$ & 1.13 & 1.08 & 1.05 & 1.00 \\
\hline$P L A N D_{S u b}$ & 30.8 & 29.4 & 62.3 & 40.2 \\
\hline$P L A N D_{U r b}$ & 25.02 & 51.0 & 14.8 & 21.9 \\
\hline CONTAG & 35.9 & 34.1 & 41.3 & 28.1 \\
\hline$P X$ & 34.3 & 102.4 & 35.9 & 13.6 \\
\hline$P X_{N}$ & 1.26 & 5.71 & 3.94 & 2.17 \\
\hline$P X S L$ & 1.17 & 10.54 & 4.43 & 1.17 \\
\hline$P X S A$ & 0.04 & 0.59 & 0.49 & 0.19 \\
\hline PXURBEXT & 25.9 & 98.56 & 19.1 & 8.8 \\
\hline
\end{tabular}

Table 3. Selected catchment descriptors and landscape metrics for four selected catchments of high urbanization.

The final set of calculated landscape metrics was added to the existing database of selected catchments and catchment descriptors, and formed the basis for the subsequent steps. To provide an overview of how the landscape metrics vary compared to the lumped index URBEXT for urban land cover, and how they are affected by scale, four catchments are selected, with key metric values detailed in Table 3, and mapping of urban and suburban areas illustrated in Figures 2 and 3. These four catchments are of broadly similar levels of urbanization as gauged by $U R B E X T_{2015}$, and provide a good example of how the spatially explicit metrics can provide additional characterization of urban land cover.

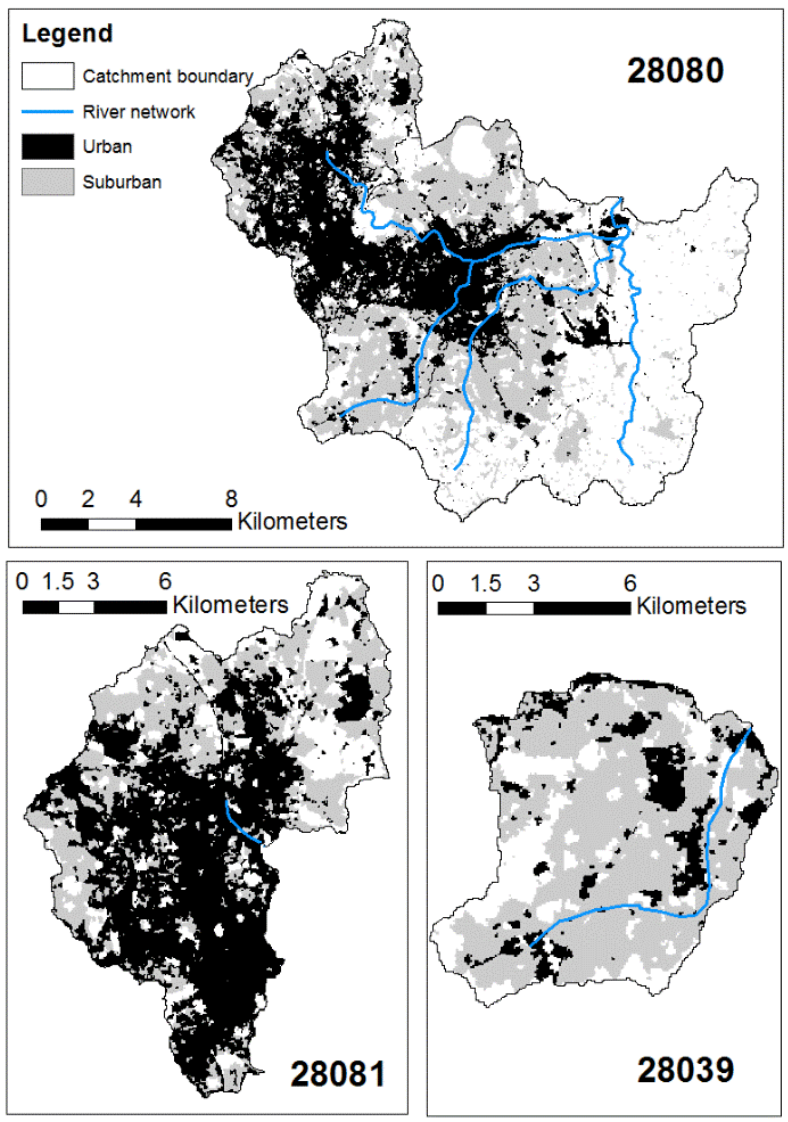

Figure 2. Land-cover mapping for the large catchment 28080 and its sub-catchments 28081 and 28039. 28080 is located in the Midlands and contains the city of Birmingham.

A comparison between the large and highly urban catchment 28080, which encompasses the city of Birmingham and much of Wolverhampton, and two of its sub-catchments (28081 and 28039: Figure 2), provides a good example of how the proximity index metrics (Table 3 ) vary across scale for highly urban catchments:

The most urban catchment, 28081 (URBEXT2015 $=$ 0.66), has the highest values for $U R B E X T_{2015}$ and all proximity index metrics across all three catchments. This reflects the fact that the catchment is almost covered in continuous urbanized areas from outlet to upper catchment, has a high proportion of Urban land cover class, and is semi-circular in shape rather than long.

- For the much larger catchment 28080, in which 28081 is situated, urban extent is reduced by some $40 \%$ compared to 28081 , but the related proximity index measures reduce more dramatically in comparison. $P X$ in 28080 is some $33 \%$ of the value in 28081 , while $P X S A$ is less than $7 \%$. This demonstrates that proximity index measures are not simply reduced by percentage of coverage, but that coverage location in 
relation to the catchment outlet and contiguousness of coverage both affect derived values. In 28080, most of the urban cover is located towards the upper and middle reaches relative to the outlet, with more fragmented land cover and large areas of rural cover in lower reaches. This highlights the distance, catchment area, and fragmentation 'penalties' applied to urbanized land cover further from the catchment outlet - decreasing relative contribution to the proximity index and related indices.

A comparison of 28080 with the smaller and less urban sub-catchment 28039 demonstrates how $P X$ can be similar for catchments of varying size and level of Urban land-cover, but then differ when length and area standardization factors are added. $P X_{N}, P X S L$ and $P X S A$ are all significantly higher in 28039 . This is due to 28039 having more continuous (sub)urban cover across all areas, with more rural areas being located in the upper-catchment, and a much lower AREA weighting reduction being applied. CONTAG is also higher than in both other catchments - reflecting the fact that clumping in highly urban catchments will generally be higher in smaller urbanized headwater catchments.

A comparison between 28039 and the similarly sized and urbanized 69043 reveals how spatial factors alone can alter landscape metric values. Located in northwest England and containing peripheral residential-industrial areas of Manchester, 69043 has a $10 \%$ lower $U R B E X T_{2015}$ than 28039 , but all proximity index values are at least $45 \%$ lower. This is a result of the urbanized land-cover being distributed more towards the edges of the catchment and further from the outlet, particularly the Urban patches, and also reflects a higher degree of overall fragmentation. In 28039, suburban and urban land-cover is distributed relatively uniformly over the catchment and patches are large and well connected

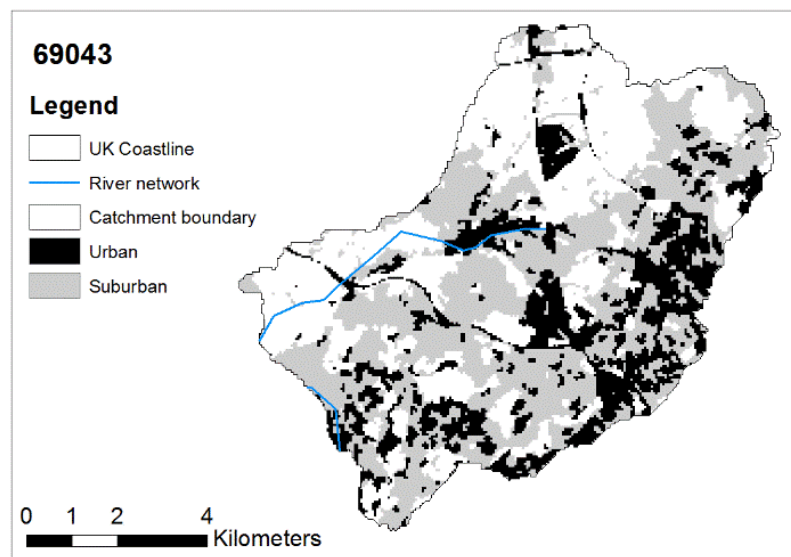

Figure 3: Land-cover mapping for catchment 69043. 69043 is located in the northwest of England.

While representing only a small fraction of the 116 total catchments, the comparison between selected catchments (Figures $2 \& 3$; Table 3 ) does provide a visual means for considering the effectiveness of the landscape metrics for additional spatial characterization of urban land-cover. This has shown the metrics to provide characterization of layout, shape, connectivity, and hydrological distance. The only concern is how low the area standardized metric $P X S A$ is for 28080. It could suggest that the metric is applying too punitive an area effect for larger catchments. The same effect is seen in other large catchments in the study dataset.

\subsection{QMED}

A few landscape metrics and catchment descriptors correlate moderately well with estimated UGF. The strongest correlation was with PXSA (Pearson's $r=0.616$ ), followed by PLANDSub $(r=0.547)$ and PLAND $D_{\text {UrbSub }}$ $(r=0.533)$. For comparison, correlations between estimated $U G F$ and the $U A F$ and PRUAF values used in the current urban adjustment procedure (WHS, 2016) were 0.550 and 0.527 respectively. Among catchment descriptors, only URBEXT2000 and $U R B E X T_{2015}$ (a nonstandard descriptor derived by applying the URBEXT methodology to LCM2015 data) had correlations with estimated $U G F$ above $0.5 \quad(r=0.523$ and $r=0.503$ respectively). The stronger correlation was with $U R B E X T_{2000}$, rather than $U R B E X T_{2015}$, presumably because the year 2000 is closer to the midpoint of more of the AMAX records used here.

Correlations between PXSA, PLAND $D_{S u b}$, PLAND $D_{\text {rbSub }}$, $U A F, P R U A F, U R B E X T_{2000}$ and $U R B E X T_{2015}$ are typically $>0.8$. The two least correlated of these are $P X S A$ and $\operatorname{PRUAF}(r=0.551)$

As $P X S A$ correlates most strongly with estimated $U G F$, an initial one-parameter urban adjustment equation using PXSA was generated (referred to as the "1-par" model):

$$
U A F_{1}=4.45^{P X S A}
$$

Due to the relatively moderate correlation between $P X S A$ and PRUAF implying that each had different explanatory powers over estimated $U A F$, a two-parameter model based on PXSA (Eq. 11) and a modified version of $P R U A F$ (Eq. 12), replacing URBEXT 2000 with $P X S A$, was generated (the "2-par" model):

$$
\begin{gathered}
U A F_{2}=P R U A F_{2}{ }^{0.455} 2.942^{\text {PXSA }} \\
P R U A F_{2}=1+8.683^{P X S A}\left(\frac{70}{85.424-64.463 \text { BFIHOST }}-1\right)
\end{gathered}
$$

An alternative two-parameter formulation based on PXSA and PLANDSub was also produced (the "2-par alt" model:

$$
U A F_{2 a}=P L A N D_{S u b}{ }^{0.045} 2.678^{P X S A}
$$

\subsection{Model performance}

Table 4 reports sum-of-squared errors, sum-ofabsolute errors, standard deviation of residuals, minimum residual and maximum residual for all three new models, the current model of urban adjustment and the baseline, asrural case. 


\begin{tabular}{|l|l|c|c|c|c|}
\hline Model & $\begin{array}{c}\text { sum } \\
\text { sq. err. }\end{array}$ & $\begin{array}{c}\text { sum } \\
\text { abs. err. }\end{array}$ & $\begin{array}{c}\text { s.e. } \\
\text { resid. }\end{array}$ & $\begin{array}{c}\text { min. } \\
\text { resid. }\end{array}$ & $\begin{array}{c}\text { max. } \\
\text { resid. }\end{array}$ \\
\hline 1-par & 7.764 & 23.161 & 0.2598 & -0.671 & 0.637 \\
\hline 2-par & 6.176 & 20.772 & 0.2328 & -0.736 & 0.525 \\
\hline 2-par alt. & 6.700 & 21.473 & 0.2424 & -0.773 & 0.563 \\
\hline current & 7.451 & 21.394 & 0.2557 & -0.698 & 0.863 \\
\hline none & 13.748 & 29.520 & 0.3443 & -0.636 & 1.202 \\
\hline
\end{tabular}

Table 4. Performance statistics for new and existing urban adjustment models and baseline case.

Table 4 demonstrates that all models show a significant improvement over the as-rural case and therefore that adjusting $Q M E D$ to account for the effects of urbanization is clearly justified. The new 2-parameter model based on $P X S A$ and modified PRUAF is shown to outperform the current model and both of the other new models according to any performance statistic except minimum residual. However, all models increase the magnitude of the minimum residual over the as-rural case, since negative residuals correspond to catchments where the gauged estimate of $Q M E D$ is less than the ungauged as-rural estimate.

Error! Reference source not found. plots gauged estimates of $Q M E D$ against ungauged as-rural estimates (as-rural; top panel), ungauged estimates adjusted using the current $U A F$ (current; middle panel) and ungauged estimates adjusted using the new 2-parameter $U A F$ (2-par, bottom panel). It is clear from the top panel that the gauged urban estimates are typically higher than the ungauged asrural estimates. Similarly, the least-squares line on the middle panel shows that the gauged $Q M E D$ estimates are still typically slightly higher than those given by the current urban adjustment method i.e. current $U A F \mathrm{~s}$ are slightly too low. The bottom panel shows improvement over the middle panel; $r^{2}$ is increased somewhat in relative terms and the least-squares line is concurrent with the 1:1 line, showing that $U A F$ s estimated using the new 2parameter model are, on average, correct.

Despite the improved performance of the new 2parameter $U A F$, it is worth noting that it can give values below 1 in catchments with both low PXSA and low $B F I H O S T$ values. The current method, by contrast, never estimates values below 1 . However, the $U A F$ estimated by the new 2-parameter model is above 1 for all 116 of the calibration catchments and, more generally, for all catchments where BFIHOST $+2.5 P X S A \geq 0.24$.

\begin{tabular}{|l|c|c|c|c|}
\hline Method (year) & $\begin{array}{c}\text { Sites } \\
(\boldsymbol{n})\end{array}$ & $\begin{array}{c}\text { Annual } \\
\text { maxima }\end{array}$ & $\begin{array}{c}\text { Standard } \\
\text { error }\end{array}$ & $\begin{array}{c}\text { Model } \\
\text { fit }\left(\boldsymbol{r}^{2}\right)\end{array}$ \\
\hline 2-par (2020) & 116 & 5558 & 0.233 & 0.331 \\
\hline Kjeldsen (2010) & 200 & 7401 & $\begin{array}{c}0.352 \\
(0.251)\end{array}$ & $\begin{array}{c}0.36 \\
(0.221)\end{array}$ \\
\hline FEH (1999) & 115 & $\sim 3000^{* *}$ & $\begin{array}{c}0.507^{*} \\
(0.264)\end{array}$ & $\begin{array}{c}0.194 \\
(0.138)\end{array}$ \\
\hline
\end{tabular}

Table 5. Standard error and $r^{2}$ for each $U A F$ model

calibration version - the 'current' model is a recasting of the

Kjeldsen (2010) model. Bracketed italic values indicate the standard error and $r^{2}$ for earlier models using the 116 catchments in this study (* FEH standard error derived from reported $f s e$ for the urban model: $\mathrm{IH}, 1999$ - Volume 3, 18.1, ** estimated from IH flood peaks database).
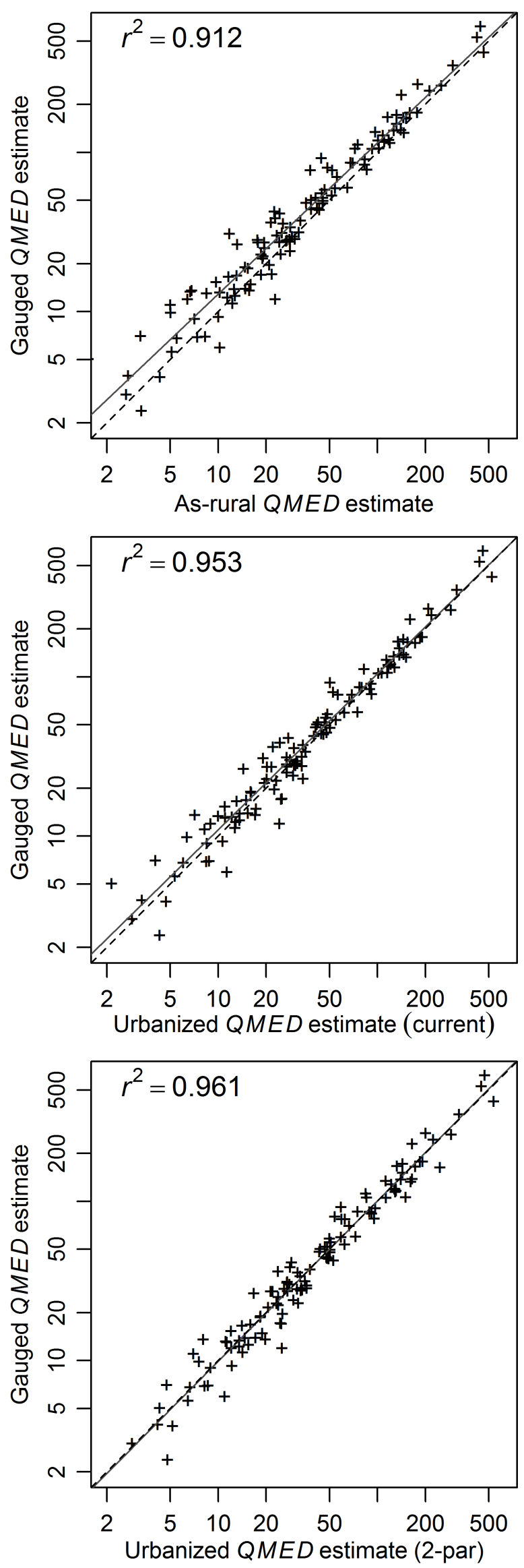

Figure 4. Gauged vs. estimated $Q M E D$ for as-rural, current and new 2-parameter urbanization methods. Black line is leastsquares, dashed line shows 1:1 relationship. 
A comparison between the updated urban model (2par) developed here (Table 5) and earlier calibrations of $U A F$ reveals substantial improvements that do not directly result from increasing availability of catchment annual maxima data. The initial FEH model used approximately 3000 annual maxima across 115 urban catchments. The standard error was quite high (0.507) and model fit low $\left(r^{2}=0.194\right)$. They found the urban adjustment provided a significant but only small improvement over the rural model (IH, 1999). Kjeldsen (2010) replaced the descriptor SPRHOST with BFIHOST and added a substantial number of sites, totalling 200 with 7401 annual maxima. Interestingly, six urban catchments were removed, all located around northwest London, in which the as-rural estimate of $Q M E D$ was significantly larger than the observed value. Residual error was reduced to 0.352 and model fit increased to $r^{2}=0.36$. The last major update to the method (Current: WHS, 2016) was a re-expression of the method developed by Kjeldsen (2010) to remove the potential issue of PRUAF tending towards infinity in extremely permeable catchments. The new 2-par model used a similar number of sites to the FEH (116) but more annual maxima (5558) as more years of data were available. The standard error of residuals was further reduced, to 0.233 , but model fit dropped slightly, to $r^{2}=0.331$.

\subsection{Flood risk impacts}

To assess the potential impacts on flood risk of the application of landscape metrics, and the revised urbanization adjustment in particular, we show how the revised QMED estimates change the 100-year return period peak flow, $Q_{100}$, across study catchments. Figure 5 presents ungauged estimates of the 100-year flood made with three variants of the FEH statistical method: as-rural with donor transfer from six donors, adjusted using the current urban adjustment factor, and adjusted using the new 2-parameter $U A F$. The coloured straight lines minimize squared error to the corresponding coloured points. Figure 5 demonstrates that estimates of $Q_{100}$ made using the new $U A F$ are typically slightly higher than those made using the current $U A F$, as suggested in Error! Reference source not found.. Proportionally, the greatest effects of urbanization, as well as the greatest differences between the new and existing $U A F \mathrm{~s}$, occur in smaller catchments.

To demonstrate the potential effects of applying the revised $U A F$ on flood risk in small catchments, Catchment 37033 is presented as a case study in Figure 6. The use of $P X S A$ provides a more suitable means for characterizing the urbanized surfaces and impacts on peak flow. The high $P X S A$ value quantifies the fact the urbanized surfaces are widespread, connected and cover a high proportion of a relatively small $\left(<10 \mathrm{~km}^{2}\right)$ catchment. This has the effect of doubling the estimated $Q M E D$, proving an estimate $\left(4.28 \mathrm{~m}^{3} \mathrm{~s}^{-1}\right)$ that is more in line with one obtained from the observed data $\left(5.06 \mathrm{~m}^{3} \mathrm{~s}^{-1}\right)$. The resulting impact on the estimated 100-year flood is considerable, increasing it from $5.3 \mathrm{~m}^{3} \mathrm{~s}^{-1}$ to $10.7 \mathrm{~m}^{3} \mathrm{~s}^{-1}$. This could subsequently require a relative increase in the design flood estimate used for any infrastructure such as a bridge near to the outlet or housing in this vicinity. This could also require a reassessment of whether current infrastructure requires upgrading or redesigning to meet the revised flood estimate.

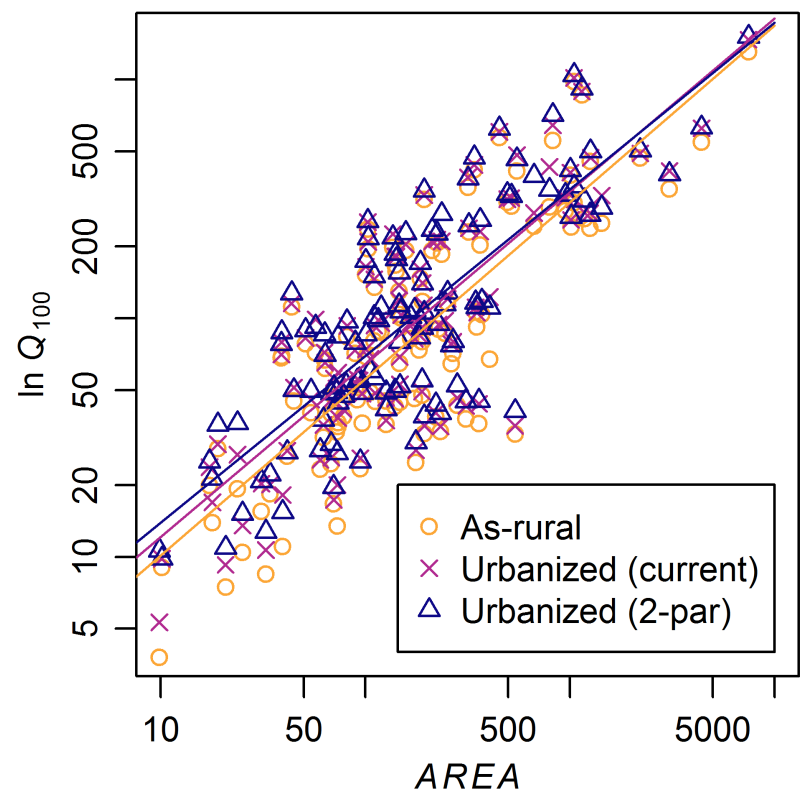

Figure 5. $Q_{100}$ (100-year flood) against catchment area: asrural (yellow), urbanized with current $U A F$ (pink) and urbanized with new 2-parameter $U A F$ (blue).

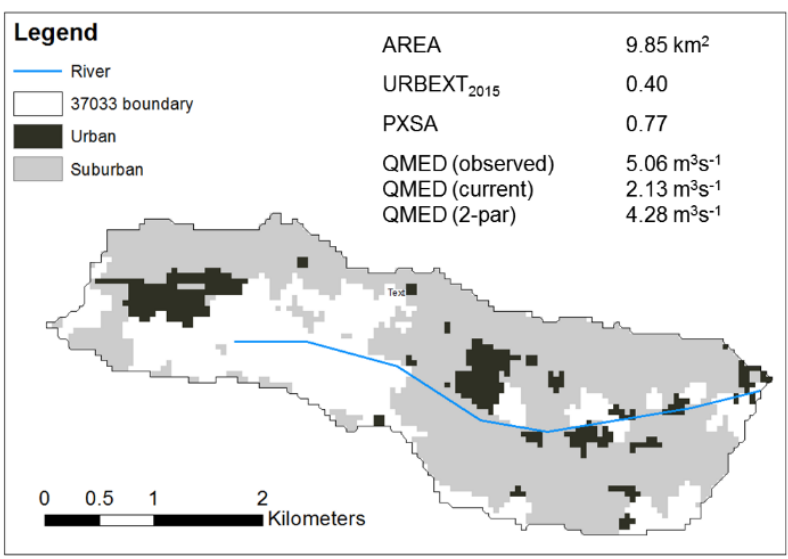

Figure 6. Land cover mapping of catchment 37033 - with detail on key catchment descriptors, derived PXSA, and QMED as estimated from observed data and both the current and new 2-parameter $U A F$ models.

\section{Discussion}

\subsection{Refining the catchment selection criteria}

The number of catchments used in this study is one more than the 115 used in the original urban adjustment factor $(U A F)$ calibration undertaken in the Flood Estimation Handbook (IH, 1999). However they only used catchments where URBEXT1990 exceeds 0.05 and did not apply any other criteria. It is estimated that they would have had around 3000 annual maximum flows in this 
dataset. Kjeldsen (2010) included catchments where $U R B E X T_{2000}$ exceeds 0.03 . This resulted in a larger pool of 206 sites, of which six were excluded, and also more years of peak flow data - some 7401 annual maximum values. At 5558 years of annual maximum values, the pool of data used in this study is clearly smaller but there has been a specific attempt to remove less-suitable catchments and also to remove sites where the as-rural estimate of $Q M E D$ is significantly higher than the urban estimate derived from observed data. The selection criteria were based on assessing whether factors identified in other papers could be used to refine the datasets used for calibrating $U A F$ and improving estimates of $Q M E D$ in urban catchments.

The primary criterion common to all methods was a threshold urban extent above which catchments are classified as urbanized. In common with Kjeldsen et al. (2010) we used a value of $U R B E X T_{2000}=0.03$, which has been shown by Miller \& Grebby (2015) to be representative of the catchment having 3\% impervious surface coverage. We used the current urban extent estimates provided in FEH methods (Bayliss et al., 2006), which are for the year 2000 and use the 2000 version of the Land Cover Map. While not directly comparable for technical issues, more recent estimates of UK land cover provided by the 2015 version (LCM2015: Rowland et al. 2017) show there was a clear overall increase in urban extent across almost all selected sites, with an average increase of $20 \%$ over the 15 year period. Given the increases observed across the sites used it would be interesting to see how many unused sites crossed the 0.03 URBEXT threshold between 2000 and 2015. However, we would not recommend using these sites as they would only be suitable if they had been urbanized for a significant duration of the available record of annual maxima. Using an urbanization threshold value at the year 2000 sits well within the general timeframe of records.

A related question concerns whether the URBEXT threshold of 0.03 is suitable, as generally urbanization effects on peak flows become apparent at a much higher level of urbanization (Brun \& Band, 2000; Miller \& Hess, 2016). Given the findings of this study, the URBEXT threshold should perhaps be related to catchment area discussed later.

An additional criterion that was employed in this study was to require a minimum record length of 10 years. This provides a more robust set of $Q M E D$ estimates from observed data, and is much longer than the minimum 3 years used by Kjeldsen et al. (2010). While even shorter records can be used to estimate $Q M E D$, we arbitrarily picked 10 years to reduce uncertainty in the estimates. This seems validated by findings from the Environment Agency report into use of local data for flood estimation, which suggests that 10 years of data is sufficient to ensure an $f$ se in gauged $Q M E D$ below 1.431 except in very extreme cases (Environment Agency, 2017b: Figure 2.6). 1.431 is the $f$ se of the FEH statistical $Q M E D$ regression model for ungauged sites.

Another criterion used in this paper involved soil permeability as estimated by BFIHOST - we removed the most permeable catchments $(B F I H O S T \geq 0.65)$, where runoff is primarily a function of baseflow. This is because the FEH statistical model used to provide as-rural estimates for $Q M E D$ performs less consistently on urbanized permeable catchments (Vesuviano et al., 2016). In such catchments, the effect of urbanization would be greater as research has shown that highly permeable catchments are more sensitive to changes in impervious cover (Shuster et al., 2005). The approach thus seems valid, however a related issue is that BFIHOST is included in the current and updated PRUAF equations, so refining the catchment data set by BFIHOST reduces the spread of BFIHOST values that can be used in the calibration and potentially reduces the model's validity in permeable catchments.

Our final criterion involved excluding sites in which the as-rural estimate of $Q M E D$ was more than $10 \%$ greater than the observed $Q M E D(U G F<0.9)$, and for which gauged data were assessed as being suitable. The basis of this was that the original calibration noted that $42 \%$ of all sites used had an observed $U G F$ less than 1 (IH, 1999). Updated calibrations of $U A F$ did remove 6 sites on a similar basis (Kjeldsen, 2010) but the refining process used here resulted in the removal of 25 sites. Given that we only applied this to the more extreme differences and performed a site-by-site assessment of gauged data using National River Flow Archive information (nrfa.ceh.ac.uk) we are confident that this has improved the suitability of the data used for the calibration of the urban adjustment factor without biasing the selection of sites. It was clear for many of the rejected sites that the as-rural estimate was too high; in some cases it was higher than any gauged flow.

One clear issue observed in this paper is the geographical bias in the dataset of suitable catchments. Given that all of Northern Ireland, and large swathes of Scotland, Wales, and east and southwest England are unrepresented in the 116 catchments used (Figure 1) it could be considered that any calibration of $U A F$ has a higher degree of uncertainty for application in such areas. This issue is not easy to resolve as the selection is first a function of where urban areas are located and then where suitable gauging station data are available in these urban areas. This lack of good quality gauged urban data has been highlighted in recent reporting to the Environment Agency (Stewart et al. 2019), and is an acknowledged limiting factor for improving accuracy in urban flood estimation.

\subsection{Landscape metrics and flood estimation}

There has been recent growing interest in the potential for using landscape metrics in hydrological applications, to improve characterization of catchment urbanization in attribution studies or lumped hydrological modelling that typically represents urbanization through generalized measures of urban extent. Of particular interest has been the use of more hydrologically relevant metrics that consider hydrological distance and catchment shape (Van Nieuwenhuyse et al., 2011; Yuan et al., 2015), particularly where these can improve on lumped urban measures (Miller \& Brewer, 2018; Oudin et al., 2018). The suite of spatially explicit landscape metrics of urban land-cover across the 116 catchments here are difficult to assess directly against measures such as URBEXT or 
imperviousness. Taken together, the results show a high degree of variability in metrics employed with respect to urban extent, as shown by Miller \& Brewer (2018), and validate their application as a means of providing a more spatially explicit characterization of urbanization for lumped catchment approaches.

More detailed analysis across a group of four highly urbanized catchments at different scales provided a more direct and visual analysis of how such spatial metrics compare to URBEXT. This demonstrated that the proximity index variants tested here all provide means of characterizing urban-land cover with respect to catchment shape and hydrology, and the layout of urban patches. Importantly, it was shown that for catchments of similar size and urban extent, which would currently be considered equally urban in the most recent $\mathrm{FEH} U A F$ equation (Wallingford HydroSolutions, 2016), the various proximity index metrics provide additional characterization that reflects variability in catchment shape, distribution of urban surfaces, and connectivity of urban surfaces. This matches the wider literature, which suggests that these factors are important for the generation of runoff and peak flows (Mejía \& Moglen, 2009; Zhang $\&$ Shuster, 2014; Oudin et al, 2018).

While the selected landscape metrics have shown variable characterization of urban land cover with respect to $U R B E X T$, there is some uncertainty over the scaling effect of $A R E A$, used in $P X S A$, when applied to larger catchments. The AREA-scaled proximity index $P X S A$ appears overly affected by the normalization by catchment area in larger catchments, such that $P X S A$ values are extremely low in comparison with smaller, less urban sites. The implications of this will be discussed with respect to estimates for the longer return period floods. What is likely required is that the area scaling effect is applied nonlinearly, however further work is required to assess how it should be applied for larger sites.

The performance of the updated 2-par model has been shown to improve upon the current (Wallingford HydroSolutions, 2016) model for $U A F$ (Table 4), with the standard error of residuals reducing by $9 \%$, from 0.2557 to 0.2328 . For context, this is equivalent to an $18 \%$ reduction in the 95 percent confidence interval of the predicted $U A F$, which is therefore reducing uncertainty in flood estimates. The only area in which performance decreases compared to the as-rural or current model is the minimum residual. However, this is completely expected, as the maximum residual corresponds to the largest value of $\ln (U G F / U A F)$ and the minimum residual corresponds to the smallest value of $\ln (U G F / U A F)$. We expect the as-rural case to have the smallest magnitude of minimum residual, because $U A F$, the denominator in $\ln (U G F / U A F)$, is 1 when there is no adjustment, and above 1 when any urban adjustment is applied. The magnitude of the minimum residual will therefore always increase for all urbanization models. The most extreme negative residuals correspond to catchments where the gauged estimate $Q M E D_{o b s}$ is less than the ungauged as-rural estimate i.e. $\ln (U G F)$ is negative. In these cases, increasing the ungauged estimate through urban adjustment increases the amount by which the ungauged estimate of $Q M E D$ exceeds the gauged estimate of $Q M E D$. Large negative residuals will therefore exist as long as there are sites where the as-rural estimates $Q M E D_{\text {rural }}$ are higher than observed $Q M E D_{\text {obs. }}$. While we removed some of the most extreme sites where $U G F$ $\left(Q M E D_{\text {obs }} / Q M E D_{\text {rural }}\right)$ was less than 1,26 sites where this ratio was below 1 still remained.

The fact that minimum residual was lower in the current model relates to the fact the 2-par model has optimized the model $Q M E D$ estimate in line with gauged estimates - providing a more symmetrical distribution against the 1:1 line between modelled $Q M E D$ estimate and gauged $Q M E D$ estimate for the updated 2-par $U A F$ model over the current $U A F$ model (Figure 4 ). The calibration has used a refined dataset with fewer catchments where $U G F$ is less than 1 and brought in landscape metrics to improve urban characterization. The current model slightly underestimates urbanized $Q M E D$ when compared to gauged $Q M E D$ for values below around 20 cumecs.

The results presented here for the new 2-par $U A F$ model show some significant improvements in model calibration over previous methods and related data (Table 5). While the improvement over the original FEH calibration was expected due to increased data and a refined set of criteria, the significant improvement over Kjeldsen et al. (2010) was surprising given the number of catchments and annual maxima being much lower. This provides good evidence that there is potential merit in refining the sites used according to suitable criteria. Caution should be applied in attributing improvements to the use of specific the landscape metrics as the datasets used for calibration differ. This is evident from Table 4, where the current model performance as applied to this selection of catchments has a higher standard deviation of residuals $(0.256)$ than the updated 2-par model (0.233). A more direct comparison of the earlier models on the same 116 catchments (Table 5) reveals that the improvement in standard error of residuals is not so significant but the fit to observed data is much higher for the updated 2-par model than for earlier models.

\subsection{Implications for Flood Risk}

The results from this study show that peak flow estimates for small urban catchments can be improved by considering more spatially explicit information to characterize urbanization effects beyond simply degree of coverage. For the smaller catchments in this study $\left(A R E A<100 \mathrm{~km}^{2}\right)$, the effect on events such as the $100-$ year flood is to significantly increase the peak flow estimates for almost all sites (Figures $5 \& 6$ ). For larger catchments $\left(A R E A>500 \mathrm{~km}^{2}\right)$, the overall effect is negligible, with estimates increasing for some catchments and decreasing for others. Thus, we can say that the use of landscape metrics for flood estimation could raise peak flow estimates in small urban catchments and improve design estimates, but not consistently so in larger catchments. This is in line with modelling studies that suggest that spatial concentrations of impervious surfaces influence peak flows (Yeo et al., 2017), and validates empirical but geographically limited results from Miller \& Brewer (2018), who found landscape metrics to be useful for improving estimates of $Q M E D$ in two clusters of small 
catchments in the River Thames basin. The linkages between floods and catchment morphologic characteristics is an emerging area of research for flood risk (Jato-Espino et al., 2018; Oudin et al., 2018). The implications are that, as Miller \& Brewer (2018) suggest, a one-size-fits-all national approach to flood risk assessment may not always be suitable, and that instead scale-relevant approaches that build in spatial elements need to be considered.

There have been a number of concerns raised about the performance and suitability of the FEH statistical method in small urban catchments (Faulkner et al., 2012; Vesuviano et al., 2016; Stewart et al., 2019). This paper demonstrates that the FEH methods used in the UK have, in response, been in continual development to render improvements for the user that reduce uncertainty and improve estimates of flood risk (e.g. Kjeldsen et al., 2010; Wallingford HydroSolutions, 2016). While much of this to date has revolved around tweaking catchment descriptors and model coefficients, or adding more catchments and peak flow data for calibration, this paper provides some new insights and avenues of research that could lead to future improvements.

Firstly, the original FEH $U A F$ calibration (IH, 1999) had a low $r^{2}$, with unexplained error being large relative to the fitted values. Further, despite a high proportion of catchments with $U G F$ less than one, there was no attempt to remove potentially erroneous sites where the observed as-rural estimate of $Q M E D$ was much greater than that estimated from gauged data. This paper suggests that filtering out potentially erroneous sites and employing landscape metrics could reduce uncertainty and provide more alignment between gauged and ungauged estimates of urban $Q M E D$, particularly for smaller urban catchments.

Secondly, a number of studies have pointed towards the value of being able to differentiate between spatial distributions of land use types for flood estimation in ungauged urban catchments (Wan Jaafar \& Han, 2012; Kjeldsen et al., 2013; Vesuviano \& Miller, 2019). This research has clearly demonstrated that landscape metrics could better characterize spatial properties of land classes for lumped catchment approaches such as flood estimation in small urban catchments. It provides a wider-scale validation of geographically limited findings from Miller \& Brewer (2018) and this should be further tested across a range of scales to assess the potential scope to develop variable-scale and urbanization-dependant methods that go beyond a one-size-fits-all approach.

Lastly, it has been shown that the statistical method underestimates $Q M E D$ for catchments with very high urbanization and permeability (Vesuviano et al., 2016). While there is some basis in our filtering out of the most permeable urban catchments, further work is required to understand the effect of this filtering when applying the method to catchments that are both urbanized and permeable, and whether a different method is more suitable for such situations. Given that BFIHOST remains part of the PRUAF equation, and thus an important variable for considering urbanization impacts across variable catchments, we cannot yet be sure of the effect of excluding permeable catchments from the calibration.

\section{Conclusions}

Flood estimation methods for ungauged urbanized catchments, as used in the UK Flood Estimation Handbook (FEH) statistical method, rely on peak flow data from urbanized sites and basic characterization of urban extent to model the effect of urbanization on the median annual flood, $Q M E D$. Limitations in the peak flow and catchment descriptor data used for such means have been identified, and while improvements have been made, further work is needed to expand the peak flow data available for urban catchments and to refine existing urban catchment descriptors. This research has built upon emerging science on the role that spatial differences in land cover have on peak flows to demonstrate the ability of landscape metrics to provide more spatially explicit and meaningful characterization of urban areas within hydrological catchments. In addition, and the study has sought to explore how refining the calibration dataset can overcome limitations identified with previous calibrations.

Overall, the refined list of catchments and spatially explicit urban land-cover characterization used in this study reflect a novel exploration for an objective means of improving flood estimates and flood risk in ungauged urban catchments. The results point to the potential value in refining catchment datasets to exclude less-suitable data in order to reduce associated uncertainty in flood estimates. They also further demonstrate the value of considering the spatial arrangement of urban land cover, particularly in smaller urban catchments. We conclude that it is not always beneficial to have more data, but to have the most suitable data for the application, and that this could be dependent on scale or level of urbanization. Landscape metrics could certainly be more suitable than lumped measures of urban extent or imperviousness, and they offer an exciting opportunity to bridge the gap between lumped and distributed hydrological modelling and to improve urban flood risk estimates.

\section{References}

1. Bayliss, A.C. (1999). Catchment descriptors (volume 5 of the Flood Estimation Handbook). Wallingford: UK Centre for Ecology \& Hydrology.

2. Bayliss, A.C., K.B. Black, A. Fava-Verde and T.R. Kjeldsen (2006). URBEXT2000 - A new FEH catchment descriptor. Calculation, dissemination and application. London: Defra (Department for Environment, Food and Rural Affairs)

3. Brun, S.E. and L.E. Band (2000). Simulating runoff behavior in an urbanizing watershed. Computers, Environment and Urban Systems 24(1), 5-22.

4. Environment Agency (2017a). Flood estimation guidelines. Bristol: Environment Agency.

5. Environment Agency (2017b). Making better use of local data in flood frequency estimation: report SC130009/R. Bristol: Environment Agency.

6. Faulkner, D., T. Kjeldsen, J. Packman and L. Stewart (2012). Estimating flood peaks and hydrographs for small catchments: Phase 1. Bristol: Environment Agency. 
7. Frazier, A.E. and P. Kedron (2017). Landscape Metrics: Past Progress and Future Directions. Current Landscape Ecology Reports 2(3), 63-72.

8. Institute of Hydrology (1999). Flood Estimation Handbook (five volumes). Wallingford: UK Centre for Ecology \& Hydrology.

9. Kjeldsen, T.R. (2010). Modelling the impact of urbanization on flood frequency relationships in the UK. Hydrology Research 41(5): 391-405.

10. Kjeldsen, T.R., D.A. Jones and A. Bayliss (2008). Improving the FEH statistical procedures for flood frequency estimation. Bristol: Environment Agency.

11. Kjeldsen, T.R., D.A. Jones and D.G. Morris (2014). Using multiple donor sites for enhanced flood estimation in ungauged catchments. Water Resources Research 50: 6646-6657.

12. McGarigal, K. and B.J. Marks (1994). FRAGSTATS: spatial pattern analysis program for quantifying landscape structure. General Technical Report PNWGTR-351. Portland, OR: U.S. Department of Agriculture, Forest Service, Pacific Northwest Research Station.

13. Mejía, A.I. and G.E. Moglen (2009). Spatial Patterns of Urban Development from Optimization of Flood Peaks and Imperviousness-Based Measures. Journal of Hydrologic Engineering 14(4): 416-424.

14. Miller, J.D. and T. Brewer (2018). Refining flood estimation in urbanized catchments using landscape metrics. Landscape and Urban Planning 175: 34-49.

15. Miller, J.D. and T. Hess (2017). Urbanisation impacts on storm runoff along a rural-urban gradient. Journal of Hydrology 552: 474-489.

16. Miller, J. D. and S. Grebby (2015) Mapping long-term temporal change in imperviousness using topographic maps. International Journal of Applied Earth Observation and Geoinformation 30: 9-20.

17. Miller, J.D., H. Kim, T.R. Kjeldsen, J. Packman, S. Grebby and R. Dearden (2014). Assessing the impact of urbanization on storm runoff in a peri-urban catchment using historical change in impervious cover. Journal of Hydrology 515: 59-70.

18. Morton, D., C. Rowland, C. Wood, L. Meek, C. Marston, G. Smith, R. Wadsworth and I.C. Simpson (2011). Final Report for LCM2007 - the new UK land cover map. Countryside Survey Technical Report No 11/07. Lancaster: Countryside Survey.

19. Ogden, F.L., N. Raj Pradhan, C.W. Downer and J.A. Zahner (2011). Relative importance of impervious area, drainage density, width function, and subsurface storm drainage on flood runoff from an urbanized catchment. Water Resources Research 47: W12503.

20. Oudin, L., B. Salavati, C. Furusho-Percot, P. Ribstein and M. Saadi (2018). Hydrological impacts of urbanization at the catchment scale. Journal of Hydrology 559: 774-786.

21. Redfern, T.W., N. Macdonald, T.R. Kjeldsen, J.D. Miller and N. Reynard (2016). Current understanding of hydrological processes on common urban surfaces. Progress in Physical Geography 40(5): 699-713.

22. Rowland, C.S., R.D. Morton, L. Carrasco, G. McShane, A.W. O'Neil, and C.M. Wood (2017) Land Cover Map 2015 (vector, GB). NERC Environmental Information Data Centre.

23. Roy, A.H. and W.D. Shuster (2009). Assessing Impervious Surface Connectivity and Applications for Watershed Management. JAWRA Journal of the American Water Resources Association 45(1): 198209.

24. Shuster, W.D., J. Bonta, H. Thurston, E. Warnemuende and D.R. Smoth (2005). Impacts of impervious surface on watershed hydrology: A review. Urban Water Journal 2(4): 263-275.

25. Stewart, E.J., D.S. Faulkner, G. Formetta, A.B. Griffin, T. Haxton, I. Prosdocimi, G. Vesuviano, A.R. Young (2019). Estimating flood peaks and hydrographs for small catchments. Report SC090031/R0, Joint Flood and Coastal Erosion Risk Management Research and Development Programme, Environment Agency, Bristol. Accepted October 2019.

26. Turner, M.G., R.H. Garner and R. O'Neill (2001). Landscape Ecology in Theory and Practice. New York: Springer.

27. Vesuviano, G. and J.D. Miller (2019). Design flood estimation and utility of high-resultion calibration data is small, heavily urbanized catchments. Journal of Flood Risk Management 12(2): e12464.

28. Vesuviano, G., L. Stewart, T. Haxton, A. Young, T. Hunt, P. Spencer and M. Whitling (2016). Reducing uncertainty in small-catchment flood peak estimation. E3S Web of Conferences 7: 1008.

29. Wallingford HydroSolutions (2016). WINFAP 4 Urban adjustment procedures. Wallingford: Wallingford HydroSolutions.

30. Zhang, Y. and W. Shuster (2014). Impacts of Spatial Distribution of Impervious Areas on Runoff Response of Hillslope Catchments: Simulation Study. Journal of Hydrologic Engineering 19(6), 1089-1100. 